\title{
Article
}

\section{Diversity and Distribution of Xylophagous Beetles from Pinus thunbergii Parl. and Pinus massoniana Lamb. Infected by Pine Wood Nematode}

\author{
Xu Chu ${ }^{1,2,3,+}$, Qiuyu Ma 1,2,3,†, Meijiao Yang 1,2,3, Guoqiang Li ${ }^{1,2,3}$, Jinyan Liu ${ }^{1,2}$, Guanghong Liang 1,2, \\ Songqing $\mathrm{Wu}^{1,2}$, Rong Wang ${ }^{1,2}$, Feiping Zhang ${ }^{1,2, *}$ and $\mathrm{Xia} \mathrm{Hu}^{1,2,3, *}$ \\ 1 Forestry College, Fujian Agriculture and Forestry University, Fuzhou 350002, China;

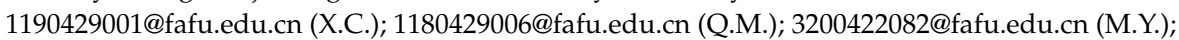 \\ 1200429002@fafu.edu.cn (G.L.); 000d040092@fafu.edu.cn (J.L.); guanghong.liang@fafu.edu.cn (G.L.); \\ songqingwu@fafu.edu.cn (S.W.); wrong-insect@fafu.edu.cn (R.W.) \\ 2 Key Laboratory of Integrated Pest Management in Ecological Forests, Fujian Agriculture and Forestry \\ University, Fuzhou 350002, China \\ 3 International Joint Laboratory of Forest Symbiology, Fujian Agriculture and Forestry University, \\ Fuzhou 350002, China \\ * Correspondence: fpzhang@fafu.edu.cn (F.Z.); lake-autumn@fafu.edu.cn (X.H.); Tel.: +86-591-8370-0261 (F.Z.); \\ +86-183-5006-8276 (X.H.) \\ + These authors contributed equally to this work.
}

\section{check for} updates

Citation: Chu, X.; Ma, Q.; Yang, M.; Li, G.; Liu, J.; Liang, G.; Wu, S.; Wang, R.; Zhang, F.; Hu, X. Diversity and Distribution of Xylophagous Beetles from Pinus thunbergii Parl. and Pinus massoniana Lamb. Infected by Pine Wood Nematode. Forests 2021, 12, 1549. https://doi.org/10.3390/ f12111549

Academic Editor: Dariusz J. Gwiazdowicz

Received: 7 October 2021

Accepted: 8 November 2021

Published: 9 November 2021

Publisher's Note: MDPI stays neutral with regard to jurisdictional claims in published maps and institutional affiliations.

Copyright: (c) 2021 by the authors. Licensee MDPI, Basel, Switzerland. This article is an open access article distributed under the terms and conditions of the Creative Commons Attribution (CC BY) license (https:/ / creativecommons.org/licenses/by/ $4.0 /)$.
Abstract: The vectors of pinewood nematode of Bursaphelenchus xylophilus (Steiner \& Bührer, 1934) are mainly known as xylophagous beetles. Understanding the composition and distribution of these xylophagous beetles in host pine trees infected by PWN is critical to control the spread of PWN. In this study, we investigated the community structures of the xylophagous beetles in two main host trees in Fujian and Shandong, Pinus massoniana Lamb. and Pinus thunbergia Parl., in different stages of infection. All beetles were collected by dissecting the whole pine trees and then identified by their morphological characteristics and COI genes. The results showed that the diversity of xylophagous beetles was different not only between the two host pine trees but also among the different infection stages. The diversity of $P$. massoniana xylophagous beetles was significantly higher than that of $P$. thunbergii, and there were also significant differences in the different stages of PWN infection. In total, Scolytinae was the most common (53.70\%), followed by Curculionidae $(18.26 \%)$, Cerambycidae $(16.31 \%)$, and Cleridae (6.04\%). Monochamus alternatus, the most important vector of PWN, occupied a large niche and showed different aggregation positions during the three infection stages in both host trees. This result might be related to the resistance of bark beetles to host trees and competition with other xylophagous beetles. The community diversity of xylophagous beetles was jointly affected by both the infection stages of PWN and the spatial niche of xylophagous beetles. Knowledge of the diversity and competitive relationships among xylophagous beetles might help regulate the population dynamics of these beetles.

Keywords: xylophagous beetles; distribution; Bursaphelenchus xylophilus

\section{Introduction}

Pine wilt disease (PWD) is an internationally recognized destructive disease of pine trees caused by pinewood nematode (PWN). Infected pine trees quickly lose water and wilt to death in a short time [1,2]. Due to its strong pathogenic ability and rapid transmission, PWD is difficult to cure once pine forests are infected, which poses a great threat to China's forest ecosystem $[3,4]$. This disease has spread to 726 county administrative regions among the 18 provinces in China, covering an area of 1.8092 million hectares and producing a cumulative number of dead pine trees close to 19.47 million [5]. Pinus massoniana (Lamb, 1803) and Pinus thunbergii (Parl, 1868) are important afforestation trees in the north and 
south of China, respectively, and are also the main host trees of Bursaphelenchus xylophilus (Steiner and Buhrer 1934). Therefore, to protect these pine forests, it is urgent to control the transmission of B. xylophilus.

Pine forests have long suffered a complex disease caused by pine wood nematode, carrier insects, other xylophagous beetles, associated fungi, bacteria, and forest abiotic factors $[6,7]$. The transmission of diseases mainly depends on vector insects carrying pathogen and transferring them to trees [8]. Although all reported vectors of B. xylophilus are currently Monochamus spp., Orthotomicus erosus (Wollaston, 1857) was previously reported to be a carrier of Bursaphelenchus teratospicularis (Kakuliya, 1966) and Bursaphelenchus sexdentati (Braasch, 2001), while Pityogenes sp. was reported to be a carrier of Bursaphelenchus leoni (Baujard, 1980) $[9,10]$. Therefore, in addition to M. alternatus, other xylophagous beetles might also be potential carriers of B. xylophilus.

The natural transmission of disease is tightly linked with the life history of its insect vectors and spread through the dispersal of adult beetles [11,12]. Therefore, the spatial distribution and dynamic variation of xylophagous beetles on diseased trees are important indicators of the disease [13]. Interestingly, the colonization of xylophagous beetles is often accompanied by competition [14,15], including competition for space and nutrient resources [16]. Xylophagous beetles colonizing pine trees encounter interspecific and intraspecific competition from conspecifics, other cerambycids, and other wood-inhabiting insects that can alter species distributions within trees [17]. In addition, most beetles are more likely to invade weakened pine trees; and the community structure of xylophagous beetles on pine trees was greatly changed after the colonization of pine wood nematode [18]. One of the most important factors causing a decline in pine tree vigor is the colonization of B. xylophilus and xylophagous insects [19-22]. Therefore, the diversity was also not only affected by the species of the host trees, but also the tree vigor. Study of biological ecological regulation of the xylophagous insects population plays an important role in successful implementation of chemical or biological control to vectors of PWN. However, the coexistence and competition relationship of these wood-inhabiting beetles was not clear enough in infected pines.

In this research, to understand the colonization sites (phloem and xylem) and colonization sequences of xylophagous beetles on pine trees, we investigated the species richness and spatial distribution of these beetles along PWN-infected tree boles during different stages of the disease. The analysis results of the spatial dynamic patterns of populations and the interspecific relationships between xylophagous beetles at different infection stages after PWN infection could provide valuable insights into the mechanisms of their change dynamics, which would help determine potential carriers of PWN. Understanding the interspecific relationships would also provide a basis for controlling the population of xylophagous beetles [23,24].

\section{Materials and Methods}

\subsection{Study Area}

From July to November 2019, we randomly selected pines infected with PWN in a P. massoniana forest of Fujian province and a P. thunbergii forest of Shandong Province. The infection stages were identified according to the growth of the pine trees infected by PWN, the colors of the pine needle leaves, the number of bite marks and wormholes, and the isolation of B. xylophilus [25-27]. We divided the P. massoniana and P. thunbergii infected by B. xylophilus into three stages: the initial stage of infection (weak wood); the medium stage of infection (dying wood); and the terminal stage of infection (a withered tree). In the initial stage of infection, some pine needles were yellow and withered, and the bole had insect bite marks, but the tree still had vitality and water, along with greater pine-resin exudation. In the medium stage of infection, the pine needles turned red and withered over a large area, the tree basically withered, the bole was dry, the borers increased, and the exudation of pine resin decreased. At the terminal stage, the needles largely fell off, 
the bark was dry, there were pits and insect excreta in the phloem, the tree lost its water completely, and no resin exudation was observed (Figure A1).

\subsection{Sampling Design}

We cut trees close to the ground without damaging the tree crowns, and the residual root pile did not exceed $5 \mathrm{~cm}$. We then measured and recorded the tree height and DBH. Low-speed drills were used to collect wood at $1.5 \mathrm{~m}$ from the base of the bole and at the crown, and pine wood nematodes were collected from wood samples using the Baermann funnel method and identified by the PCR test methods described in Wei et al. and morphological characteristics to determine whether the pine was infected with pine wood nematode disease [28,29]. Primers for partial ribosomal-DNA-large-subunit D2/D3 (LSU D2/D3) were forward-primer D2a (5'-ACAAGTACCGTGAGGGAAAGT-3') and reverse-primer D3b (5'-TGCGAAGGAACCAGCTACTA-3') [29]. The identification of B. xylophilus was based on diagnostic morphological characteristics. The whole pine was divided into three equal positions according to the height: the upper part, the middle part, and the bottom part. The felled boles were divided by chain saw into one-meter sections. We recorded the number of cavities on the felled bole; then, all insect samples were manually obtained directly from galleries of the infested pine trees using fine forceps; placed into centrifugal tube and store in 96-well frozen storage box; and labeled with the host pine, infection stage, feeding site, and location of the log. Three infected pines were sampled for each stage, and three replicates were used at each sampling site. A total of 27 infected pine trees was collected per site. We then calculated the volume of the truncated wood pine and counted the insect population in each meter of wood. We recorded the species, number, and distribution of insects in the bole. The xylophagous beetles were stored at $4{ }^{\circ} \mathrm{C}$ until use.

\subsection{Xylophagous Beetle Identification}

Morphological identification of the collected xylophagous beetles was accomplished under a stereomicroscope based on external morphological characteristics. These samples were preliminarily identified to the genera and species levels [27]. The cytochrome oxidase subunit I (COI) gene was used for molecular identification of the xylophagous beetles, as described in previous studies [30,31]. We extracted total DNA from 3-5 of each beetle according to morphology and placed each head separately in a centrifuge tube. Then, we used the CTAB method to extract DNA. Next, the purity and concentration of DNA were determined and the DNA was stored at $-25^{\circ} \mathrm{C}$. The primers were LepF (5'-ATTCAACCAATCATAAAGATATTGG-3') and HCO2198 (5'-TAAACTTCAGGGTGAC CAAAAAATCA- $\left.3^{\prime}\right)$. The PCR reactions were conducted in a final volume of $50 \mu \mathrm{L}$ containing $25 \mu \mathrm{L}$ of $2 \times$ Taq PCR Master Mix, $2.5 \mu \mathrm{L}$ of $0.5 \mu \mathrm{mol} / \mathrm{L}$ of each primer, $10 \mu \mathrm{L}$ of nuclease-free water, and $10 \mu \mathrm{L}$ of the DNA template [30]. The PCR products were electrophoretically detected on agarose gel with a concentration of $1 \%$. The PCR products were sequenced at the Boshang sequencing company of Fuzhou, and the sequences were deposited in GenBank (MT811991-MT812011). The homologous sequences were screened and the phylogenetic tree was constructed using the MEGA version 5.05 (Mega Limited, Auckland, New Zealand, 2011). For molecular identification, we used NCBI database to perform blast alignment on the obtained sequences, and the morphological identification was based on the described in "Insect Taxonomy" [32]. The PCR test methods described above was applied in the detection of pine wood nematode in xylophagous beetles collected in this research; thirty insects were detected in each species. All samples were detected for those insects with a low number not reaching thirty [30].

\subsection{Functional Diversity}

Functional diversity was calculated based on the locations and diets of the beetles using Rao's diversity index (Rao, 1982; Ricotta, 2005). To account for differences in the number of individuals collected at each site, species richness was rarefied using the Ve- 
gan package, version 1.15-0, implemented in the R-statistical environment, version 2.7.1 (Lucent Technologies, Murray Hill, NJ, USA, 2008).

\subsection{Statistical Analyses}

To compare the species and abundance of xylophagous beetles under different forest types, the effects of different infected P. massoniana and P. thunbergii trees were analyzed through a one-way ANOVA test and an independent-sample T-test. The number of species (richness) and individual number (abundance) of xylophagous beetles on P. massoniana and $P$. thunbergii trees in different infection stages were calculated according to the positions of bole colonization by xylophagous beetles, and the Shannon diversity indices were calculated for the different infection stages. The calculation formulas were as follows:

$$
\text { Niche breadth : } B_{i}=1 /\left(n \sum P_{i k}^{2}\right) \mathrm{a}=1 \text {, }
$$

where $B_{i}$ is the niche width of the $i$ th species, $n$ is the value of the niche resource levels, and $P_{i k}$ is the proportion of the individuals of the $i$ th species among the total number of individuals in the total resources.

$$
\text { Nicheoverlap : } Q_{i j}=\sum\left(P_{i k} P_{j k}\right) / \sqrt{\left(\sum P_{i k}^{2} \sum P_{j k}{ }^{2}\right)}
$$

where $Q_{i j}$ is the niche overlap values of species $i$ and species $j$, and $P_{i k}$ and $P_{j k}$ are the proportion of individuals using the $k$ th resource unit of species $i$ and species $j$, respectively, compared to the total number of corresponding species in the total resources.

We adopted the dominance index of Berger-Parker (1970):

$$
d=N / N_{t}
$$

where $d$ is the dominance index, $N$ is the number of individuals in a group, and $N t$ is the number of all species.

$$
H^{\prime}=-\sum p_{i} \log p_{i}
$$

where $H^{\prime}$ is community diversity, and $p_{i}$ is the probability of the occurrence of species $i$. Community evenness was then calculated and analyzed using the formula proposed by Pielou (1966):

$$
E=H^{\prime} / \ln S
$$

where $E$ is community evenness, $H^{\prime}$ is community diversity, and $S$ is species richness. In the case of insect communities, species richness $S$ is the number of species in the community.

\section{Results}

3.1. Identification, Composition, and Diversity of Xylophagous Insects in the Forests of P. thunbergii and P. massoniana

The results of investigating P. massoniana and P. thunbergii infected with PWN were as follows: the average DBH of $P$. massoniana was $17.3 \mathrm{~cm}$ (14 $\mathrm{m}$ higher on average); the average DBH of $P$. thunbergii was $12 \mathrm{~cm}$ (12.3 $\mathrm{m}$ higher on average) (Table A1).

According to molecular identification of the COI gene and comprehensive identification of the morphological characteristics, we identified 20 species of insects. In this experiment (Figure 1), a total of 12,272 xylophagous beetles from 16 species with high richness were selected for analysis. Among them, nine species were taken from the P. massoniana forest and nine species were taken from the $P$. thunbergii forest. These species included six species in the family Curculionidae, subfamily Scolytinae, Ipidae, including Xyleborus hawaiiensis (Perkins, 1900), Orthotomicus laricis (Fabricius, 1792), Orthotomicus erosus (Nordl, 1888), Pityogenes trepanatus (Nördlinger, 1848), Pityokteines spinidens (Reitt, 1894), and Cyrtogenius luteus (Blandford, 1894), accounting for $53.70 \%$; four species in the family Cerambycidae including M. alternatus, Arhopalus rusticus (Linnaeus, 1758), Arhopalus 
unicolor (Gahan, 1906), and Cephalallus oberthuri (Sharp, 1905), accounting for 16.30\%; three species in the family Elateridea including Homotechnes brunneofuscus (Nakane, 1954), Dalopius vagus (Brown, 1934), and Tetrigus lewisi (Candèze, 1873), accounting for 4.19\%; two species in the family Curculionidae including Shirahoshizo patruelis (Voss, 1937) and Hyposipalus gigas (Fabricius, 1775), accounting for 18.26\%; and one species in the family Cleridae (Trichodes leucopsideus Olivier, 1795), accounting for $18.26 \%$. Other species belonged to Carabidae (1), Scarabaeidae (1), and Buprestidae (1).

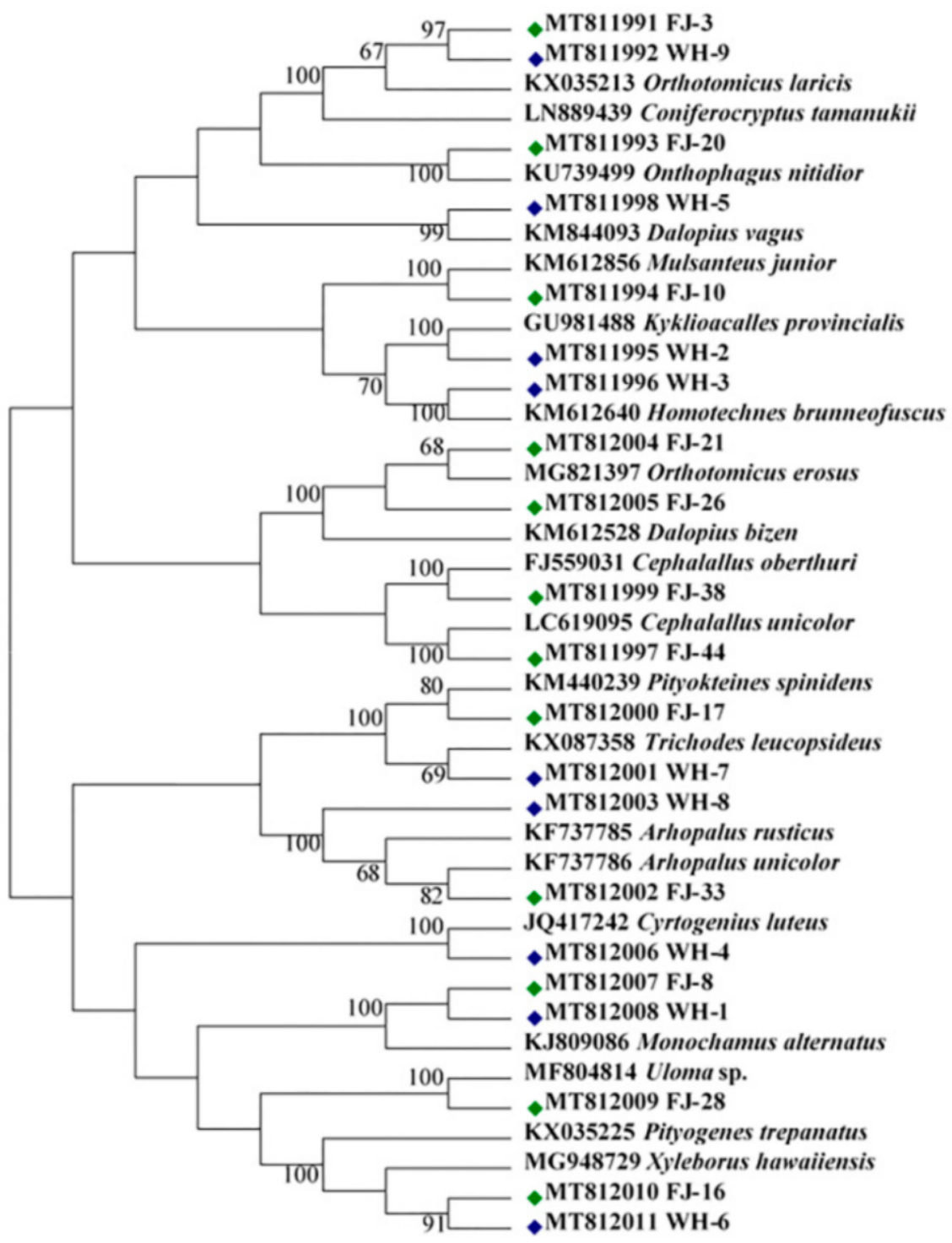

Figure 1. Phylogenetic tree based on the COI sequences of 20 xylophagous beetles collected from pine infected with PWN. FJ1-FJ12 labeled on green dots indicates xylophagous beetles collected from P. massoniana Lamb.; WH1-WH9 labeled on blue dots indicates xylophagous beetles collected from P. thunbergii Parl.; others indicate the reference sequences.

3.2. Rarefaction Curves Presenting the Relationship between the Number of Samples and Insect Species Richness in P. massoniana and P. thunbergii Forests

In this study, we analyzed a dilution curve constructed by the Shannon index (Figure 2). The results showed that the Shannon index at the species level increased with an increase in the amount of sampled data. When the amount of sampled data reached a certain value, the curve increased until becoming smooth. The sampling depth was sufficient, the amount of sampled data was reasonable, and most insect samples were covered. 


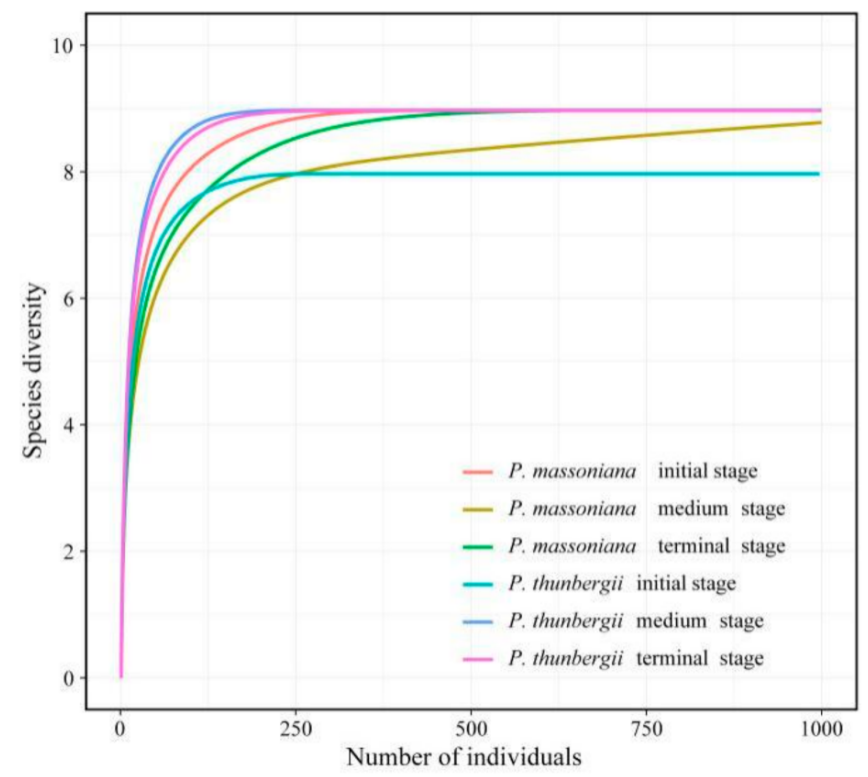

Figure 2. Rarefaction curves of the species richness level of P. massoniana and P. thunbergii at different affected stages. The red, yellow, and green curves represent the P. massoniana samples in three stages; the cyan, blue, and purple curves represent the P. thunbergii samples in three stages. Broken lines represent the $95 \%$ confidence interval for each curve.

\subsection{Community Structure of Xylophagous Beetles at Different Infection Stages in the Forests of} P. massoniana and P. thunbergii

In the P. massoniana forest, 11 insect species were identified: three species in the family Scolytinae, accounting for $54.52 \%$; one species in the family Curculionidae, accounting for $24.29 \%$; three species in the family Cerambycidae, accounting for $15.09 \%$; one species in the family Cleridae, accounting for $3.15 \%$; one species in the family Elateroidea, accounting for $0.93 \%$; and other insects accounting for $2.01 \%$ (Figure 3 ).
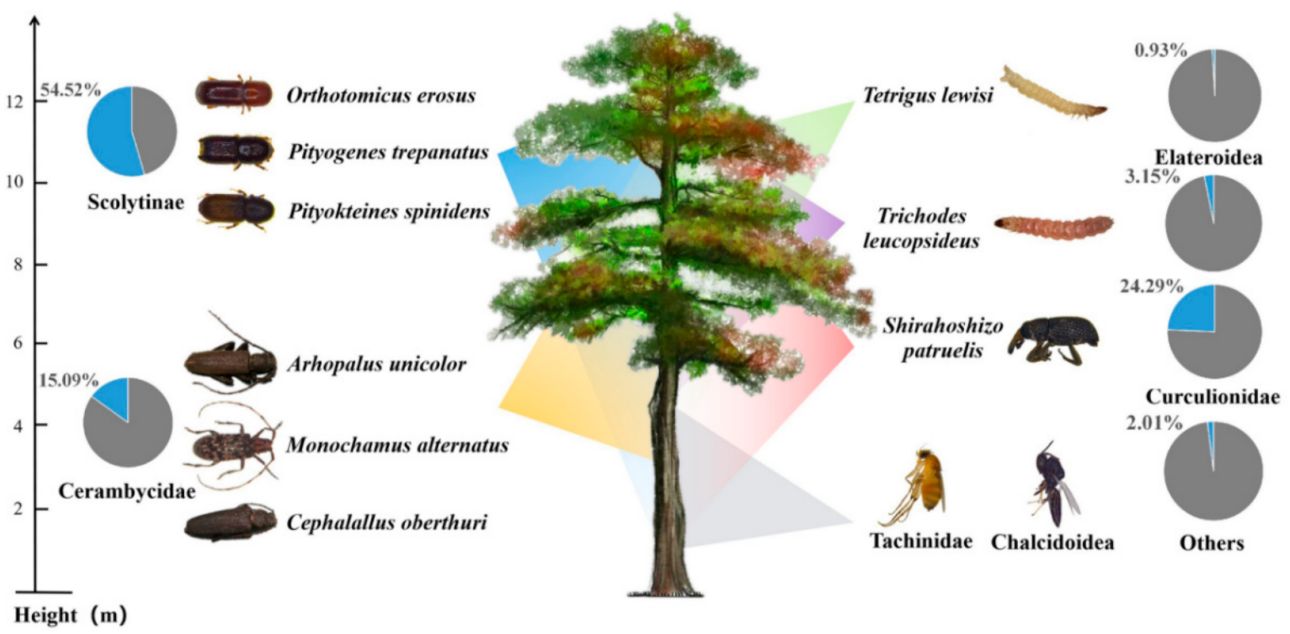

Figure 3. Diversity and distribution of xylophagous beetles and other insects in infected P. massoniana. The pie chart shows the proportion of xylophagous beetles, and the projection shows the distribution of xylophagous beetles.

In the P. thunbergii forest, nine insect species were identified: three species in the family Scolytinae, accounting for $51.43 \%$; two species in the family Cerambycidae, accounting for $19.75 \%$; one species in the family Cleridae, accounting for $14.14 \%$; two species in the family Elateroidea, accounting for $13.33 \%$; and one species in the family Curculionidae, accounting for $1.36 \%$ (Figure 4 ). 


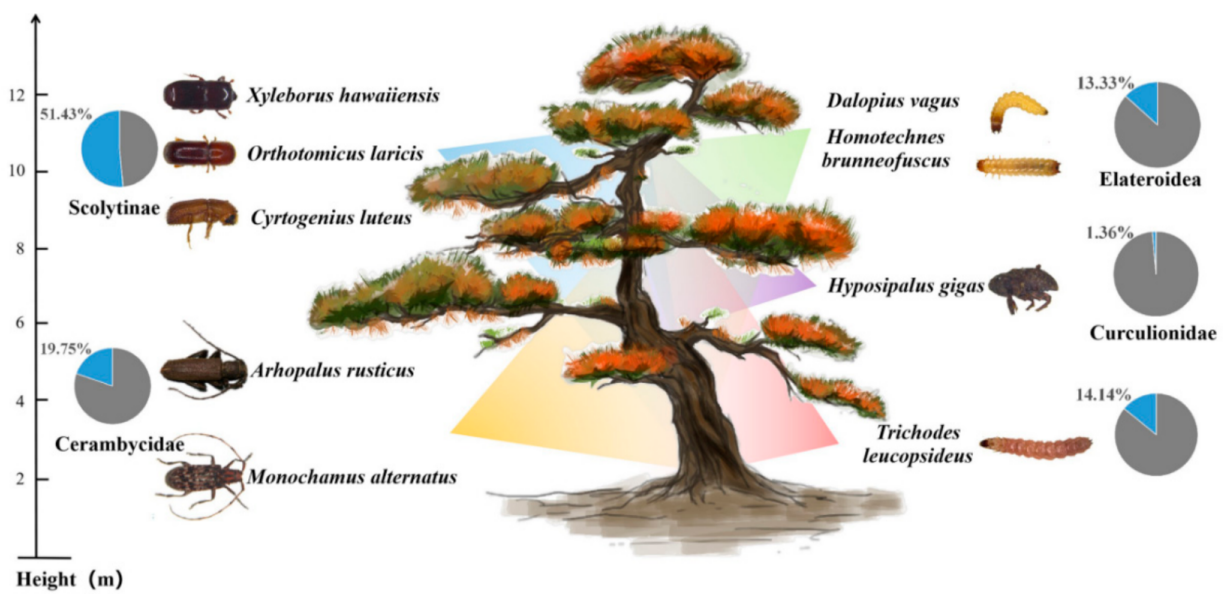

Figure 4. Diversity and distribution of xylophagous beetles in infected $P$. thunbergii. The pie chart shows the proportion of xylophagous beetles, and the projection shows the distribution of $x y-$ lophagous beetles.

In the P. massoniana forest, S. patruelis and O. erosus, the two largest populations, were distributed in different stages of pine infection, while $M$. alternatus, an important vector of pine wood nematode disease, was enriched in the upper part of the initial stage of pine infection and the middle and bottom parts of the terminal stage of infection. In the $P$. thunbergii forest, $M$. alternatus was clustered in the bottom part of the bole during the medium and terminal stages of the disease (Figure 5).

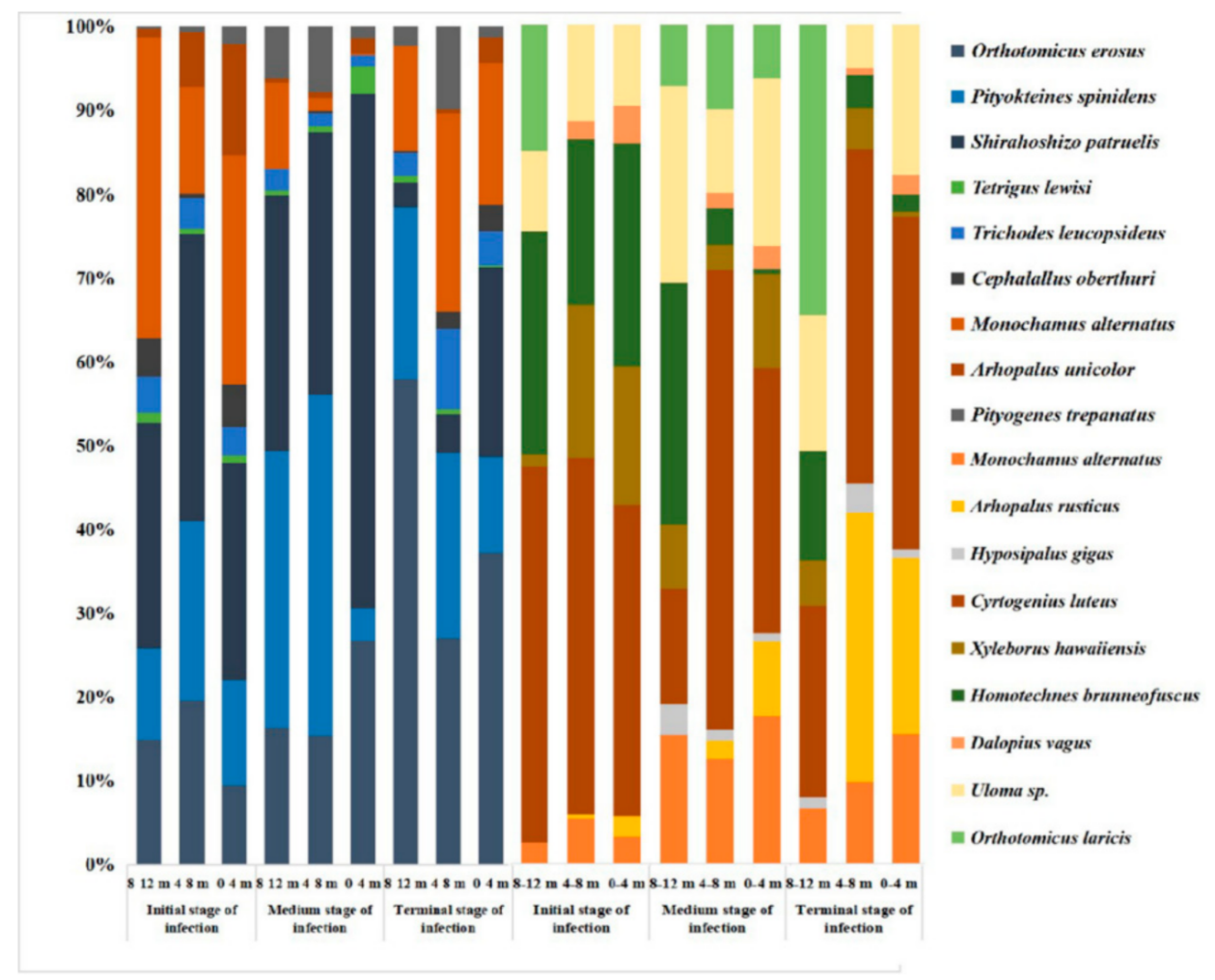

Figure 5. Composition of xylophagous beetles in the upper, middle, and bottom positions of $P$. thunbergii and P. massoniana infected by PWN at different stages.

\subsection{Identification of Dominant Insect Species and Division of the Functional Groups}

The dominant insect species of $P$. massoniana and $P$. thunbergii in different infection stages were analyzed according to the dominance index. The species were divided into 
three different functional groups: woodboring beetles, bark beetles, and predators. In the P. massoniana and P. thunbergii forests infected with PWN, bark beetles dominated, with a dominance diversity of 0.8043 and 0.6611 , respectively. Orthotomicus sp. was the dominant species, with a dominance index $(d)$ of 0.3544 and 0.1261 in P. massoniana and $P$. thunbergii, respectively. Woodboring beetles mainly lived in weak trees infected with pine wood nematode, and their dominance indexes were 0.1510 and 0.1975 , respectively. In this functional group, M. alternatus presented the largest dominance diversity of 0.8297 and 0.5416 in P. massoniana and P. thunbergii, respectively. The dominance of predators was 0.0617 and 0.1414 , respectively, in the two forests (Tables 1 and 2).

The composition of xylophagous beetles in the two forests changed significantly in the different infection stages. The diversity of xylophagous beetles in the forest increased gradually with an increase of the infection stage in the P. massoniana forest (from 0.69 to 0.79 , Table 3). According to the Shannon index, the diversity of xylophagous beetles was reduced in the terminal stage of infection in the $P$. thunbergii forest (0.66) and continued up to the terminal stage. In the medium stage, the diversity of xylophagous beetles in the P. thunbergii forest (0.76) was similar to that in the P. massoniana forest (0.79) (Figures A2 and A3 and Table 3).

Table 1. Function groups of insects and their dominance index $(d)$ in P. thunbergii Parl.

\begin{tabular}{cccc}
\hline Function Groups & $\boldsymbol{d}$ (Functional Group) & Dominant Insect Species & $\boldsymbol{d}$ (Insects) \\
\hline \multirow{2}{*}{ woodboring beetles } & \multirow{2}{*}{0.1975} & Monochamus alternatus & 0.5416 \\
& & Arhopalus rusticus & 0.4584 \\
\hline \multirow{2}{*}{ bark beetles } & \multirow{2}{*}{0.6611} & Hyposipalus gigas & 0.0206 \\
& & Cyrtogenius luteus & 0.5570 \\
& & Xyleborus hawaiiensis & 0.0947 \\
predators & Homotechnes brunneofuscus & 0.1777 \\
& \multirow{2}{*}{0.1414} & Dalopius vagus & 0.0239 \\
& & Orthotomicus laricis & 0.1261 \\
\hline
\end{tabular}

Table 2. Function groups of insects and their dominance index $(d)$ in P. massoniana Lamb.

\begin{tabular}{cccc}
\hline Function Groups & $\boldsymbol{d}$ (Functional Group) & Dominant Insect Species & $\boldsymbol{d}$ (Insects) \\
\hline \multirow{3}{*}{ woodboring beetles } & \multirow{3}{*}{0.1510} & Monochamus alternatus & 0.8297 \\
& & Arhopalus unicolor & 0.1055 \\
& & Cephalallus oberthuri & 0.0648 \\
\hline \multirow{3}{*}{ bark beetles } & \multirow{2}{*}{0.8043} & Orthotomicus erosus & 0.3544 \\
& & Pityokteines spinidens & 0.2863 \\
& & Shirahoshizo patruelis & 0.3082 \\
predators & Pityogenes trepanatus & 0.0511 \\
& \multirow{2}{*}{0.0617} & Monochamus alternatus & 0.8297 \\
\hline \multirow{2}{*}{} & & Tetrigus lewisi & 0.1536 \\
& & Trichodes leucopsideus & 0.5210 \\
\hline
\end{tabular}

Table 3. Community characteristic indexes of xylophagous beetles in P. massoniana and P. thunbergii at different infection stages.

\begin{tabular}{ccccccc}
\hline \multirow{2}{*}{ Infected Stages } & \multicolumn{3}{c}{ P. massoniana } & \multicolumn{3}{c}{ P. thunbergii } \\
\cline { 2 - 7 } & $\boldsymbol{H}^{\prime}$ & $\boldsymbol{E}$ & $\boldsymbol{S}$ & $\boldsymbol{H}^{\prime}$ & $\boldsymbol{E}$ & $\boldsymbol{S}$ \\
\hline Initial stage & $0.69 \pm 0.06$ & $0.35 \pm 0.02$ & 7 & $0.79 \pm 0.07$ & $0.36 \pm 0.04$ & 9 \\
Medium stage & $0.79 \pm 0.03$ & $0.38 \pm 0.02$ & 8 & $0.76 \pm 0.03$ & $0.37 \pm 0.06$ & 8 \\
Terminal stage & $0.79 \pm 0.02$ & $0.38 \pm 0.01$ & 8 & $0.66 \pm 0.06$ & $0.30 \pm 0.06$ & 9 \\
\hline
\end{tabular}

Note: Data are means \pm standard error (SE), $n=3$. 
3.5. Interspecific Competition among Xylophagous Beetles at Different Infection Stages in P. thunbergii and P. massoniana Forests

By comparing the niche breadth of the nine species of xylophagous beetles with the greatest population richness in each forest, we found that D. vagus occupied the main niche in the P. thunbergii forest (0.993). In the P. massoniana forest, M. alternatus had the largest niche breadth (0.909) (Table A2). In the P. thunbergii forest, T. leucopsideus and C. luteus firmly occupied the middle and bottom positions of the bole in the medium and terminal stages of the infected pine trees, spatially following $M$. alternatus, while O. laricis $(Q=0.971)$ competed with $M$. alternatus in the middle part of the bole at the specific medium stage of the disease and showed obvious aggregation behavior in the upper part of the bole at the initial and terminal stages of the disease. The niche overlap index of $O$. laricis and $M$. alternatus gradually increased over the duration of infection. Niche overlap also existed among P. spinidens, O. erosus, and T. lewisi $(\mathrm{Q}>0.969)$ (Figure 6, Table A3). In addition, O. laricis and A. rusticus showed the largest niche overlap index, which mainly occurred in the middle and bottom parts of the bole in the terminal infection stage.

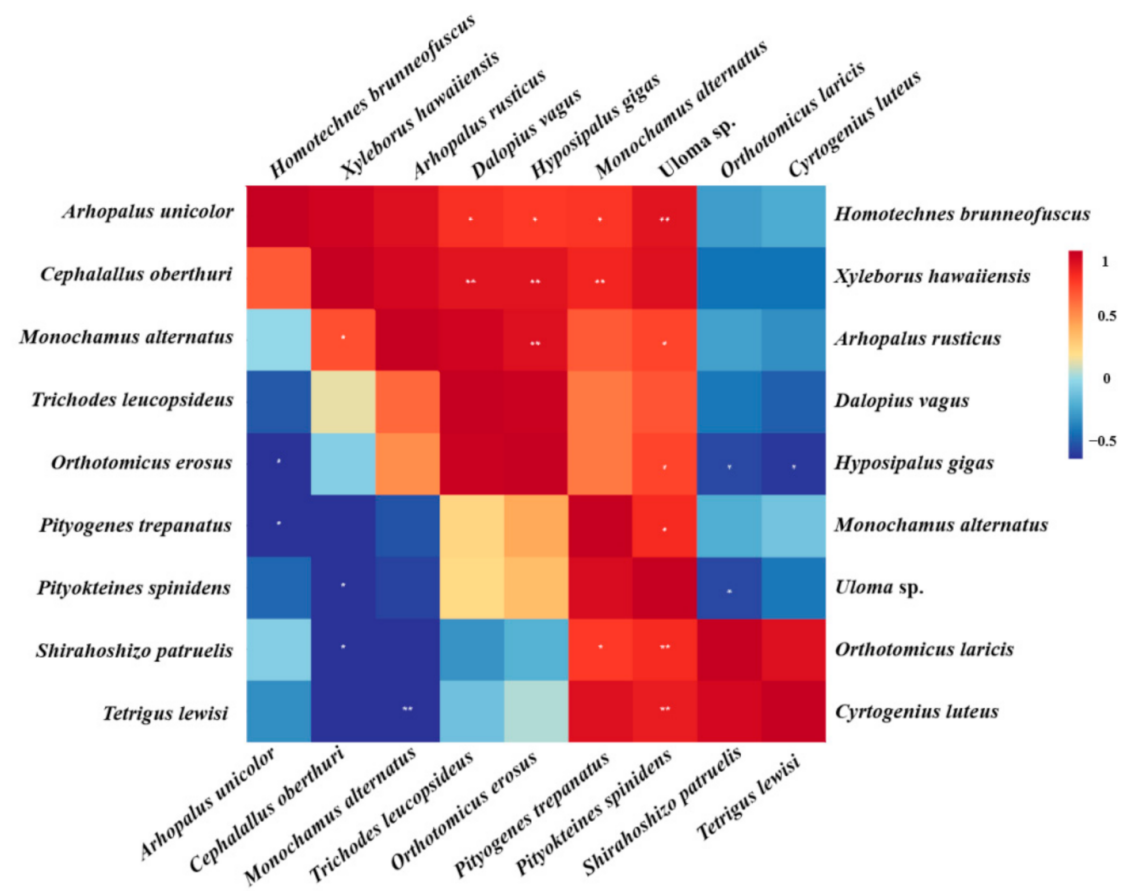

Figure 6. Correlation heat map analysis of xylophagous beetles in P. massoniana and P. thunbergii. The red color of the grid in the figure indicates that the niche overlap index between vertical and horizontal species is larger, and the blue color indicates that the niche overlap index between species is smaller; and * indicates significant ${ }^{* *}$ indicates extremely significant.

\subsection{Identification of PWN in Xylophagous Beetles}

According to the result of the PCR test and morphological characteristics, B. xylophilus was isolated from M. alternatus in both P. massoniana and P. thunbergia. No B. xylophilus was isolated from other xylophagous beetles and other insects in this research.

\section{Discussion}

In pine forests infected by B. xylophilus, the complex invasions of xylophagous beetles accelerate the death of pine trees, reduce the resistance of pine trees to B. xylophilus, and provide intermediate hosts for the transmission of PWN [33]. In our study, the composition and distribution of xylophagous beetles were surveyed in P. massoniana and P. thunbergia trees in different infection stages. Nine species of xylophagous beetles were identified in P. massoniana and P. thunbergii, respectively. In addition, two parasites were identified in P. massoniana. These parasites shared two of the same taxa: M. alternatus and T. leucopsideus 
M. alternatus and Cleridae were also reported in Pinus yunnanens infected by PWN [34]. Moreover, in the present study, no B. xylophilus was isolated from these xylophagous beetles except for M. alternatus. However, O. erosus and Pityogenes sp. were reported as carriers of Bursaphelenchus spp. [35]. More studies are needed to determine if there are other carriers of B. xylophilus besides Monochamus.

The composition and structure of xylophagous beetles were different between the two host trees species in different infection stages. The diversity of insects was affected by multiple biotic and abiotic factors, such as climate, topography, soil, host plants, and natural enemies [36]. Together, these complex factors influenced the distribution and population of xylophagous beetles in the two forests. Pine trees infected by B. xylophilus have different weakening cycles when observed in different forests, different stand ages, and different management modes, each showing different attraction effects to xylophagous beetles. For example, Blatt et al. [37] caught greater numbers of several Monochamus species in Christmas tree plantations than in adjacent forests.

Interestingly, the population of M. alternatus, an important vector of pine wood nematode disease, was enriched in the upper part of $P$. massoniana during the initial infection stage, while the middle and bottom parts were enriched in the terminal infection stage. In P. thunbergii, M. alternatus also tended to clustered in the bottom part during the medium and terminal infection stages. This phenomenon might be related to the host tree's utilization of nutritional resources via vertical migration [22]. T. leucopsideus and C. luteus were also enriched in the middle and bottom sections of the bole in the medium and terminal stages, possibly because the complex colonization of other xylophagous beetles increased the pressure of nutritional competition in the crown layer during the medium and terminal infection stages. Additionally, during the terminal stage of PWN infection, pine trees lost a great deal of water and nutrients. The canopy of the pine tree then became unsuitable for xylophagous beetles, so they migrated to the bottom part of the bole [38]. Akbulut et al. [17] also believed that the loss of water from pine bole might reduce the survival rate of xylophagous beetles.

The colonization order of insect functional groups living on pine trees also followed a certain law (from health to infection to death) for the pine wood nematode. The relative richness of $O$. erosus was found to be the highest in xylophagous beetles in P. massoniana. Moreover, O. erosus was reported to be a pioneer species [39] able to reduce the resistance and tree potential of the host pine. Subsequently, other xylophagous beetles and predators gradually enter the tree. In the different stages of infection with pine wood nematode disease (until death), insects with different functional groups occupy the dominant position. According to the dynamic analysis of the niche, M. alternatus, as a secondary pest, damaged the weakened pine trees after colonization with pioneer bark beetles such as C. luteus and $O$. erosus. Thus, colonization with M. alternatus might benefit from bark beetles. The presence of exit holes, galleries, and tunnels made by the primary colonizers subsequently has a positive effect on the species richness and abundance of secondary colonizers and their predators $[40,41]$. It was previously reported that bark beetle reaches its niche load in terms of its trophic niche during the medium stage of infection, which limits increases in the M. alternatus population [42]. Therefore, the colonization of other xylophagous beetles might affect the distribution of the M. alternatus population.

In the initial stage of infection, $M$. alternatus was found to be mainly in competition with Scolytidae, which was able to overcome the resistance of the host pine tree and further reduce the tree's vigor. In the terminal stage of infection, competition with M. alternatus was mainly provided by species such as Elateridae. At this stage, xylophagous beetles in the bole mainly played a role in accelerating the decline of the pine trees [43]. We suspect that intraspecific competition, cannibalism, and resource quality affected the survival of $M$. alternatus; otherwise, the species without a competitive advantage would be eliminated early [44].

The niche overlap between O. laricis and M. alternatus accompanied the entire infection cycle and peaked at the terminal stage. Scolytinae had a certain inhibitory effect on the 
canopy of $M$. alternatus, which together limited the population growth of $M$. alternatus. Research on xylophagous beetles in P. massoniana in Zhejiang also found that Tomicus piniperda (Scolytinae) inhibited population growth of the M. alternatus [18]. The population dynamics of $M$. alternatus might be related to the resistance of bark beetles to host trees and competition with other xylophagous beetles. In the P. massoniana forest, O. erosus and T. leucopsideus showed an obvious spatial migration phenomenon, suggesting that T. leucopsideus might be a predator of O. erosus. Ultimately, understanding the spatial distribution and interspecific relationships of xylophagous beetles in pine trees infected with B. xylophilus provides a basis for regulating the population of PWN vectors to control the transmission of PWD.

\section{Conclusions}

The diversity of xylophagous beetles was different not only between the two host pine trees but also among the different infection stages. M. alternatus and T. leucopsideus were investigated in both pines. M. alternatus, as the only vector of B. xylophilus in our research, occupied a large niche and showed a similar population fluctuation during the three infection stages in both host trees. It might be related to the cooperation and competition of other xylophagous beetles to the host defension and nutritional utilization.

Author Contributions: Data curation, X.C. and Q.M.; Investigation, X.C.; Methodology, X.H.; Project administration, F.Z.; Resources, X.H.; Supervision, M.Y., G.L. (Guoqiang Li), J.L., G.L. (Guanghong Liang), S.W., R.W. and X.H.; Writing—original draft, X.C. and Q.M.; Writing—review \& editing, Q.M. and X.H. All authors have read and agreed to the published version of the manuscript.

Funding: This research was funded by the National Key Research and Development Program of China (grant number 2017YFD0600105); the National Natural Science Foundation of China (grant numbers 31800548); the Forestry Science Research Project of Fujian Forestry Department (grant number Minlinke [2019] 16); and the Forest Science Peak Project of College of Forestry, Fujian Agriculture and Forestry University (grant numbers 71201800743).

Institutional Review Board Statement: Not applicable.

Informed Consent Statement: Written informed consent has been obtained from the patient(s) to publish this paper.

Data Availability Statement: The data presented in this study are openly available in Zenodo at 10.5281 /zenodo. 5235663 .

Conflicts of Interest: The authors declare no conflict of interest.

\section{Appendix A}

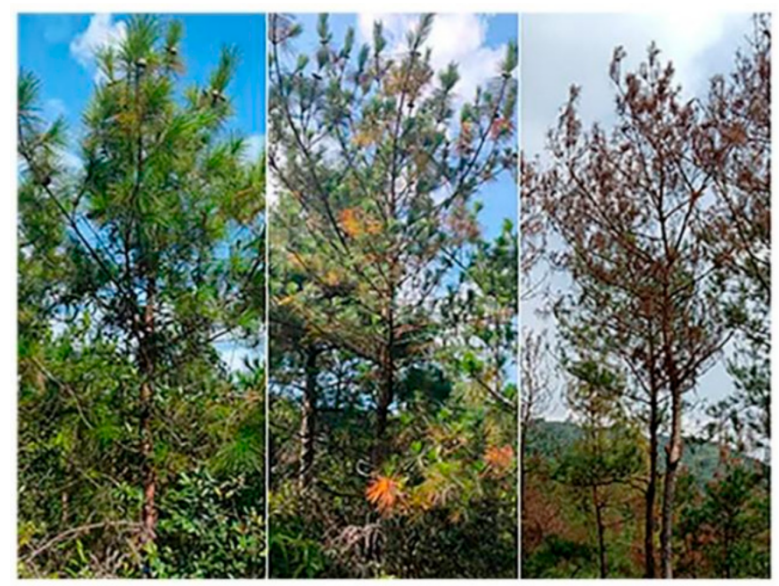

Figure A1. Three stages of pine infected with pine wood nematode disease. From left to right are the initial stage, medium stage, and terminal stage of the disease. 


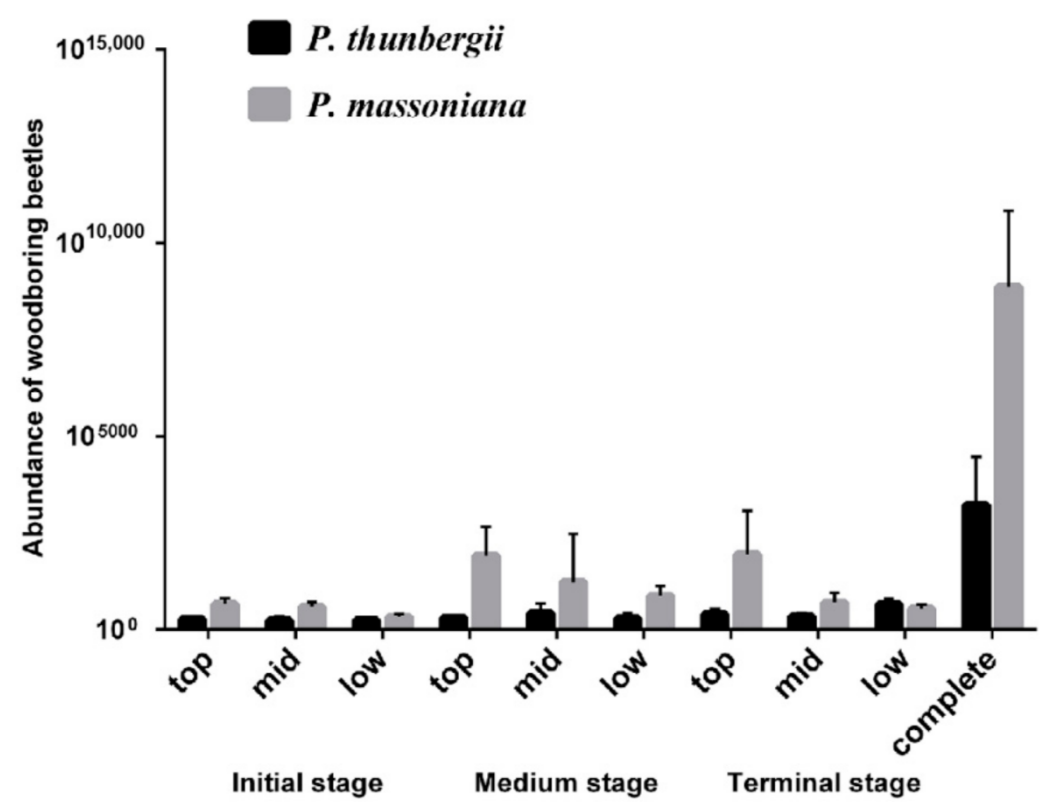

Figure A2. Abundance of xylophagous beetles in different infected stage.

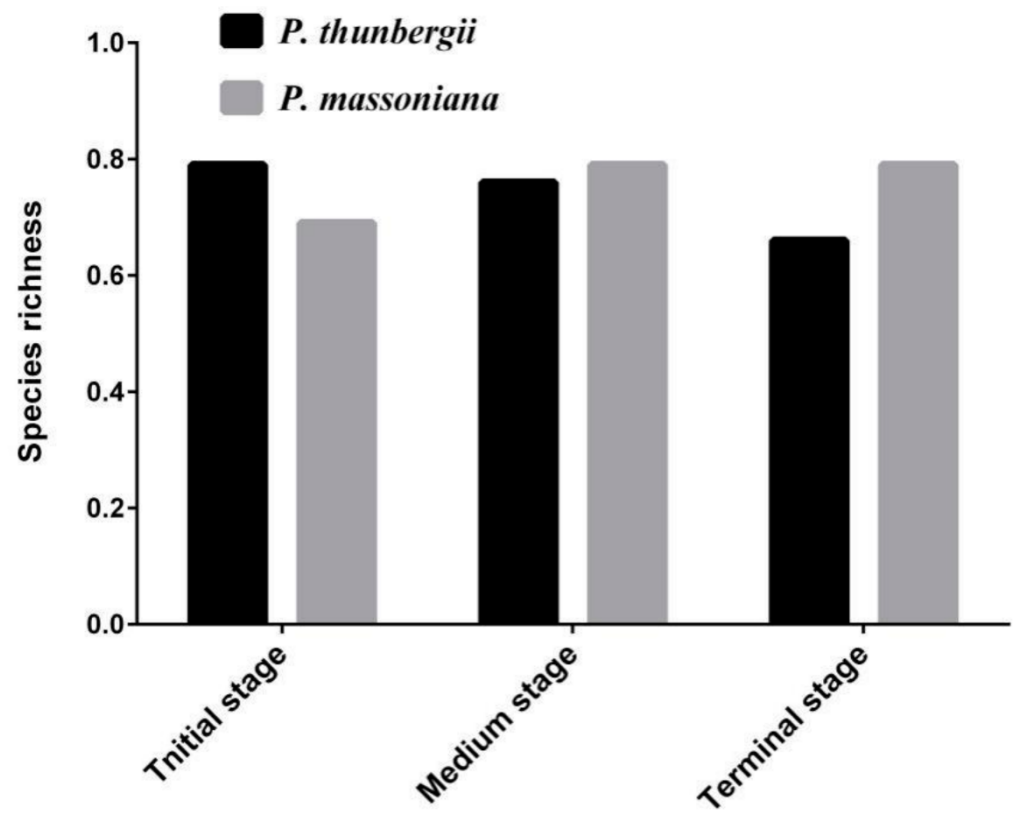

Figure A3. Species richness of xylophagous beetles in different infected stages.

Table A1. The average height, diameter at breast height (DBH), and annual ring of the sample pine trees in the infected P. thunbergii and P. massoniana.

\begin{tabular}{cccccc}
\hline Host Tree & $\begin{array}{c}\text { Forest } \\
\text { Composition }\end{array}$ & Infected Stage & $\begin{array}{c}\text { Average } \\
\text { DBH (cm) }\end{array}$ & $\begin{array}{c}\text { Average } \\
\text { Hight }(\mathbf{m})\end{array}$ & $\begin{array}{c}\text { Annual Ring } \\
\text { (Year) }\end{array}$ \\
\hline \multirow{2}{*}{$\begin{array}{c}\text { Pinus } \\
\text { thunbergii }\end{array}$} & \multirow{2}{*}{ Pure forest } & Initial stage & $9.26 \pm 3.61$ & $10.25 \pm 2.523$ & $18.7 \pm 4.2$ \\
& & Medium stage & $11.50 \pm 1.53$ & $12.01 \pm 2.650$ & $20.3 \pm 2.5$ \\
& & Terminal stage & $16.31 \pm 2.65$ & $15.24 \pm 2.082$ & $26.7 \pm 4.0$ \\
\hline \multirow{2}{*}{ Pinus } & \multirow{2}{*}{ Mingled } & Initial stage & $15.44 \pm 2.52$ & $12.63 \pm 2.659$ & $15.0 \pm 2.9$ \\
massoniana & forest & Medium stage & $17.58 \pm 3.51$ & $13.52 \pm 2.009$ & $20.0 \pm 1.1$ \\
& & Terminal stage & $20.19 \pm 4.51$ & $17.17 \pm 2.520$ & $20.1 \pm 3.6$ \\
\hline
\end{tabular}


Table A2. Niche breadth of xylophagous beetles in the infected P. thunbergii and P. massoniana.

\begin{tabular}{cccc}
\hline Beetles in P. thunbergii & Niche Breadth & Beetles in P. massoniana & Niche Breadth \\
\hline Monochamus alternatus & 0.777 & Monochamus alternatus & 0.909 \\
Cyrtogenius luteus & 0.967 & Orthotomicus erosus & 0.713 \\
Homotechnes brunneofuscus & 0.879 & Pityokteines spinidens & 0.761 \\
Orthotomicus laricis & 0.831 & Shirahoshizo patruelis & 0.630 \\
Arhopalus rusticus & 0.446 & Pityogenes trepanatus & 0.653 \\
Hyposipalus gigas & 0.661 & Tetrigus lewisi & 0.729 \\
Xyleborus hawaiiensis & 0.927 & Trichodes leucopsideus & 0.871 \\
Dalopius vagus & 0.993 & Cephalallus oberthuri & 0.703 \\
Trichodes leucopsideus & 0.892 & Arhopalus unicolor & 0.716 \\
\hline
\end{tabular}

Table A3. Niche overlap of xylophagous beetles in the infected pine trees.

\begin{tabular}{|c|c|c|c|}
\hline Beetles in P. thunbergii & Label & Beetles in P. massoniana & Label \\
\hline Monochamus alternatus & 1 & Monochamus alternatus & $\mathrm{A}$ \\
\hline Cyrtogenius luteus & 2 & Orthotomicus erosus & B \\
\hline Homotechnes brunneofuscus & 3 & Pityokteines spinidens & $\mathrm{C}$ \\
\hline Orthotomicus laricis & 4 & Shirahoshizo patruelis & $\mathrm{D}$ \\
\hline Arhopalus rusticus & 5 & Orthotomicus erosus & $\mathrm{E}$ \\
\hline Hyposipalus gigas & 6 & Tetrigus lewisi & $\mathrm{F}$ \\
\hline Xyleborus hawaiiensis & 7 & Trichodes leucopsideus & G \\
\hline Dalopius vagus & 8 & Cephalallus oberthuri & $\mathrm{H}$ \\
\hline Trichodes leucopsideus & 9 & Arhopalus unicolor & $\mathrm{I}$ \\
\hline \multicolumn{4}{|c|}{ Niche overlap index } \\
\hline Q12 & 0.933 & Qab & 0.881 \\
\hline Q13 & 0.681 & $\widehat{\mathrm{Q} a c}$ & 0.726 \\
\hline$\widehat{Q} 14$ & 0.971 & Qad & 0.576 \\
\hline$\widehat{Q} 15$ & 0.812 & $\widehat{Q}$ ae & 0.661 \\
\hline Q16 & 0.990 & Qaf & 0.704 \\
\hline Q17 & 0.741 & Qag & 0.960 \\
\hline Q18 & 0.900 & Qah & 0.925 \\
\hline Q19 & 0.986 & Qai & 0.804 \\
\hline Q23 & 0.878 & $\widehat{Q b c}$ & 0.811 \\
\hline Q24 & 0.970 & $\widehat{Q b d}$ & 0.566 \\
\hline Q25 & 0.788 & Qbe & 0.807 \\
\hline Q26 & 0.521 & Qbf & 0.736 \\
\hline Q27 & 0.899 & $\widehat{\mathrm{Qbg}}$ & 0.976 \\
\hline Q28 & 0.994 & Qbh & 0.647 \\
\hline Q29 & 0.980 & $\widehat{Q b i}$ & 0.460 \\
\hline Q34 & 0.735 & $\widehat{Q} c d$ & 0.936 \\
\hline Q35 & 0.446 & Qce & 0.992 \\
\hline Q36 & 0.578 & Qcf & 0.990 \\
\hline Q37 & 0.991 & $\widehat{Q} c g$ & 0.826 \\
\hline Q38 & 0.923 & Qch & 0.465 \\
\hline Q39 & 0.785 & Qci & 0.559 \\
\hline Q45 & 0.945 & Qde & 0.910 \\
\hline$\widehat{\mathrm{Q}} 46$ & 0.959 & $\widehat{Q} \mathrm{df}$ & 0.975 \\
\hline Q47 & 0.767 & Qdg & 0.628 \\
\hline Q48 & 0.939 & Qdh & 0.381 \\
\hline Q49 & 0.986 & Qdi & 0.624 \\
\hline Q56 & 0.849 & Qef & 0.969 \\
\hline Q57 & 0.452 & Qeg & 0.795 \\
\hline Q58 & 0.628 & Qeh & 0.366 \\
\hline Q59 & 0.812 & Qei & 0.446 \\
\hline Q67 & 0.643 & Qfg & 0.777 \\
\hline Q68 & 0.841 & Qfh & 0.475 \\
\hline Q69 & 0.959 & $\widehat{Q} \mathrm{fi}$ & 0.624 \\
\hline
\end{tabular}


Table A3. Cont.

\begin{tabular}{cccc}
\hline Beetles in $\boldsymbol{P}$. thunbergii & Label & Beetles in $\boldsymbol{P}$. massoniana & Label \\
\hline Q78 & 0.939 & Qgh & 0.784 \\
Q79 & 0.829 & Qgi & 0.642 \\
Q89 & 0.960 & Qhi & 0.994 \\
\hline
\end{tabular}

Note: 1-9 represents nine species of xylophagous beetles in the P. thunbergii forest, A-I represents nine species of xylophagous beetles in the P. massoniana forest.

\section{References}

1. Liu, G.Y.; Lin, X.; Xu, S.Y.; Liu, G.; Mu, W. Efficacy of fluopyram as a candidate bole-injection agent against Bursaphelenchus xylophilus. Eur. J. Plant. Pathol. 2020, 157, 403-411. [CrossRef]

2. Chang, D.K.; Hwa, Y.L.; Ju, H.H.; Joo, H.S.; Joon, H.S. Infection behavior and distribution of Bursaphelenchus xylophilus in Pinus densiflora trees. Forest. Sci. Technol. 2013, 9, 81-86.

3. Lu, M.; Sun, J.H. Biological Invations in Forest Ecosystem in China; Springer: Berlin/Heidelberg, Germany, 2017; Volume 11, pp. 53-66.

4. Schrader, G.; Unger, J.G. Plant quarantine as a measure against invasive alien species: The framework of the international plant protection convention and the plant health regulations in the European Union. Biol. Invations 2003, 5, 357-364. [CrossRef]

5. Li, J.H.; Pan, J.L.; Liu, C.; Cheng, T.T.; Peng, Z.C.; Yan, H. Analysis of the epidemic situation of pine wilt disease in China in 2020. For. Pest Dis. 2021, 40,1-4.

6. Zhao, L.L.; Ahmad, F.; Lu, M.; Zhang, W.; Jacob, D. Ascarosides promote the prevalence of ophiostomatoid fungi and an invasive pathogenic nematode, Bursaphelenchus xylophilus. J. Chem. Ecol. 2018, 44, 701-710. [CrossRef]

7. Zhang, W.; Meng, J.; Ning, J.; Qin, P.J.; Zhou, J.; Zou, Z.; Wang, Y.H.; Jiang, H.; Ahmad, F.; Zhao, L.L.; et al. Differential immune responses of Monochamus alternatus against symbiotic and entomopathogenic fungi. Sci. China Life Sci. 2017, 60, 902-910. [CrossRef] [PubMed]

8. Robertson, L.; García-Álvarez, A.; Arcos, S.C.; Díez-Rojo, M.A.; Mansilla, J.P.; Sanz, R.; Martínez, C.; Miguel, E.; Castresana, L.; Notario, A.; et al. Potential Insect Vectors of Bursaphelenchus spp. (Nematoda: Parasitaphelenchidae) in Spanish Pine Forests; Springer: Berlin/Heidelberg, Germany, 2008; pp. 221-234.

9. Akbulut, S.; Stamps, W.T. Insect vectors of the pinewood nematode: A review of the biology and ecology of Monochamus species. Forest Pathol. 2012, 42, 89-99. [CrossRef]

10. Linit, M.J. Nematode-vector relationships in the pine wilt disease system. J. Nematol. 1988, 20, 227-235. [PubMed]

11. Aikawa, T.; Togashi, K. Movement of Bursaphelenchus xylophilus (Nematoda: Aphelenchoididae) in tracheal system of adult Monochamus alternatus (Coleoptera: Cerambycidae). Nematology 2000, 2, 495-500. [CrossRef]

12. Togashi, K. Spatial pattern of pine wilt disease caused by Bursaphelenchus xylophilus (Nematoda: Aphelenchoididae) within a Pinus thunbergii stand. Popul. Ecol. 1991, 33, 245-256. [CrossRef]

13. Zhao, L.L.; Mota, M.; Vieira, P.; Butcher, R.A.; Sun, J.H. Interspecific communication between pinewood nematode, its insect vector, and associated microbes. Trends Parasitol. 2014, 30, 299-308. [CrossRef] [PubMed]

14. Meng, J.; Wickham, J.D.; Ren, W.L.; Zhao, L.; Sun, J.H. Species displacement facilitated by ascarosides between two sympatric sibling species: A native and invasive nematode. J. Pest. Sci. 2020, 93, 1059-1071. [CrossRef]

15. Dang, Y.Q.; Zhang, Y.L.; Wang, X.Y.; Xin, B.; Quinn, N.F.; Duan, J.J. Retrospective analysis of factors affecting the distribution of an invasive wood-boring insect using native range data: The importance of host plants. J. Pest. Sci. 2021, 94, 981-990. [CrossRef]

16. Shen, S.W.; Luo, Y.Q.; Yu, L.F.; Lu, W.J.; Han, X.G.; Ren, L.L. Temporal and spatial niches of two sympatric Tomicus species pests of Pinus yunnanensis Faranch. Chin. J. Appl. Entomol. 2018, 55, 279-287.

17. Akbulut, S.; Keten, A.; Stamps, W.T. Population dynamics of Monochamus galloprovincialis Olivier (Coleoptera: Cerambycidae) in two pine species under laboratory conditions. J. Pest. Sci. 2008, 81, 115-121. [CrossRef]

18. Song, J.Y.; Luo, Y.Q.; Shi, J.; Yan, X.; Chen, W.; Ping, J. Niche of insect borers within Pinus massoniana infected by pine wood nematode. Front. For. China 2006, 1, 460-463. [CrossRef]

19. Roe, A.D.; Torson, A.S.; Bilodeau, G.; Bilodeau, P.; Hamelin, R.C. Biosurveillance of forest insects: Part I-Integration and application of genomic tools to the surveillance of non-native forest insects. J. Pest. Sci. 2019, 92, 51-70. [CrossRef]

20. Marini, L.; Økland, B.; Jönsson, A.M.; Bentz, B.; Carroll, A. Climate drivers of bark beetle outbreak dynamics in Norway spruce forests. Ecography 2017, 40, 1426-1435. [CrossRef]

21. Escuer, M.; Abelleira, A.; Robertson, L.; Santiago, R.M.; Cobacho, S.A.; Navas, A.; Esparrago, G. Incidence of the pinewood nematode Bursaphelenchus xylophlius steiner \& buhrer, 1934 (nickle, 1970) in spain. Nematology 2011, 13, 755-757.

22. Wang, C.Y.; Fang, Z.M.; Wang, Z.; Dong, L.Z.; Li, J.G.; Mi, R.L.; Liu, L.; Chang, K.S. Biological control of the pinewood nematode Bursaphelenchus xylophilus by application of the endoparasitic fungus Esteya vermicola. BioControl 2011, 56, 91-100. [CrossRef]

23. Flaherty, L.; Gutowski, J.M.G.; Hughes, C.; Mayo, P.; Mokrzycki, T.; Pohl, G.; Silk, P.; Rooyen, K.V.; Sweeney, J. Pheromoneenhanced lure blends and multiple trap heights improve detection of bark and wood-boring beetles potentially moved in solid wood packaging. J. Pest. Sci. 2019, 92, 309-325. [CrossRef] 
24. Gao, R.H.; Song, D.W.; Huang, R.F.; Shi, J.; Luo, Y.Q.; Liu, H.G.; Chen, J.Y. Characteristics of typical Masson pine community and soil properties at the early invasive stage of pine wood nematode in the Three Gorges Reservoir Region, central China. J. Beijing For. Univ. 2015, 37, 84-91.

25. Xu, H.C.; Luo, Y.Q.; Zhang, T.T.; Shi, Y.J. Changes of reflectance spectra of pine needles in different stage after being infected by pine wood nematode. Spectrosc. Spect. Anal. 2011, 31, 1352-1356.

26. Mamiya, Y. The pine wood nematode. Helminthologia 1984, 49, 96-103.

27. Lah, E.F.C.; Yaakop, S.; Ahamad, M.; George, E.; Nor, S.M. Precise identification of different stages of a tick, Ixodes granulatus Supino, 1897 (Acari: Ixodidae). Asian. Pac. J. Trop. Bio. 2016, 6, 597-604.

28. Kaya, H.K.; Stock, S.P. Techniques in Insect Nematology. Manual of Techniques in Insect Pathology; Academic Press: Cambridge, MA, USA, 1997; pp. 281-324.

29. Wei, M.Y.; Giblin-Davis, R.M.; Baochuan, L. Molecular Characterization and Development of Real-Time PCR Assay for Pine-Wood Nematode Bursaphelenchus xylophilus (Nematoda: Parasitaphelenchidae). PLoS ONE 2013, 8, e78804.

30. Tian, H.; Yu, P.W.; Lou, Q.Z.; Xu, Z.B.; Yang, X.L.; Wang, X.J.; Hao, C.; Guo, Y.Z. Molecular identification of Dendroctonus rufipennis and D. pseudotsugae based on DNA barcoding. Plant Quar. 2020, 34, 30-34.

31. Peng, H.; Zhang, S.K.; Geng, X.S.; Fang, L.X.; Zhang, W.; Shu, J.P.; Wang, H.J. Population Differentation of Batocera lineolata (Coleoptera: Cerambycidae) Adults Whose Larvae Fed on Different Host Tree Species. Sci. Silvae Sin. 2020, 56, 91-103.

32. Cai, B.H.; Cai, X.M.; Huang, F.S. Insect Taxonomy; Chemical Industry Press: Beijing, China, 2017. (In Chinese)

33. Hammerbacher, A.; Kandasamy, D.; Ullah, C.; Schmidt, A.; Wright, L.P.; Gershenzon, J. Flavanone-3-hydroxylase plays an important role in the biosynthesis of spruce phenolic defenses against bark beetles and their fungal associates. Front. Plant Sci. 2019, 10, 208. [CrossRef] [PubMed]

34. Li, X.K.; Wang, H.X.; Jia, L.P.; Wu, J.Y.; Wu, J.R. Timing dynamic of stem-boring insects in Pinus yunnanens forest. For. Inventory Plan. 2014, 39, 68-72.

35. Lantschner, M.V.; Aukema, B.H.; Corley, J.C. Droughts drive outbreak dynamics of an invasive forest insect on an exotic host. For Ecol. Manag. 2019, 433, 762-770. [CrossRef]

36. Jung, J.K.; Park, Y.; Lee, H.; Lee, J.H.; Koh, S.H.; Choi, T.Y.; Woo, D. A comparison of diversity and composition of carabid beetles between overpasses and underpasses in fragmented forest areas. J. Asia-Pac. Entomol. 2019, 20, 1267-1277. [CrossRef]

37. Blatt, S.E.; Bishop, C.; Sweeney, J. Incidence of Monochamus (Coleoptera: Cerambycidae) species in Nova Scotia, Canada Christmas tree plantations and comparison of panel traps and lures from North America and Europe. Can. Entomol. 2019, 149, 191-203. [CrossRef]

38. Foit, J.; Čermák, V.; Gaar, V.; Hradil, K.; Nový, V.; Rolincová, P. New insights into the life history of Monochamus galloprovincialis can enhance surveillance strategies for the pinewood nematode. J. Pest Sci. 2019, 92, 1203-1215. [CrossRef]

39. Arias, M.; Robertson, L.; Garcia, A.; Arcos, S.C.; Escuer, M.; Sanz, R.; Mansilla, J.P. Bursaphelenchus fungivorus (Nematoda: Aphelenchida) associated with Orthotomicus erosus (Coleoptera: Scolitydae) in Spain. For. Pathol. 2010, 35, 375-383. [CrossRef]

40. Buse, J.; Ranius, T.; Assmann, T. An endangered long-horn beetle associated with old oaks and its possible role as an ecosystem engineer. Biol. Conserv. 2008, 22, 329-337. [CrossRef]

41. Calderon-Cortes, N.; Quesada, M.; Escalera-Vazquez, L.H. Insects as stem engineers: Interactions mediated by the twig-girdler Oncideres albomarginata chamela enhance arthropod diversity. PLoS ONE 2011, 6, e19083. [CrossRef]

42. Liu, Y.J.; Zong, S.X.; Ren, L.L.; YU, L.F.; Gao, B.T.; Sang, Z.Z.E.; Luo, Y.Q. The relationship between degrees of Pinus yunnanensis canopy dieback and the types of damage caused by specific pests. Chin. J. Appl. Entomol. 2017, 54, 947-954.

43. Zhao, S.Y.; Erbilgin, N. Larger resin ducts are linked to the survival of lodgepole pine trees during mountain pine beetle outbreak. Front. Plant Sci. 2019, 26, 1459. [CrossRef] [PubMed]

44. Kahuthia, R.; Abonyo, A.; Imbayi, B. Composition and diversity of xylophagous and predatory beetles in Vachellia xanthophloea (Benth.) P.J.H.Hurter (Fabales: Fabaceae) at Kenyatta University and Mitaboni, Kenya. J. Asia-Pac. Biodivers. 2019, 12, $217-222$. [CrossRef] 